\title{
STUDENTS' PERCEPTION TOWARDS THE USE OF REWARDS TO ENHANCE THEIR LEARNING BEHAVIOURS AND SELF-DEVELOPMENT
}

\author{
Kamron Phungphai, \\ kamron@rr.ac.th \\ King Mongkut's University of Technology, Thailand \\ Atipat Boonmoh, \\ atipat.boo@kmutt.ac.th \\ King Mongkut's University of Technology, Thailand
}

\begin{abstract}
Rewarding system and reinforcement have often been used in language teaching, and they have been used to help improve students' academic achievements, and learning competition and control desirable behaviours in the English learning classroom. This exploratory study investigates students' perceptions of the use of rewards in the classroom for enhancing behaviours and selfdevelopment. Participants were 29 mattayom 5 high school students (Grade 11) who studied a fundamental English course in Samut Sakhon Province on the outskirts of Bangkok. The rewarding system was then designed to be used during the 12-week sessions. The course was divided into 3 phases, and each phase lasted for 4 weeks. No rewards were given to students in the first phase, and all rewards were given in the second and third phases. At the end of week 4,8 and 12, participants were required to write reflective journals to examine their perceptions toward the use of rewards. The journals were analysed via thematic content analysis. The findings revealed that receiving rewards influenced students' positive emotions - enjoyment, excitement, relaxation and engagement. The findings also showed that they were highly satisfied with the use of rewards which enhanced their self-development since a teacher used them as external goals. Rewards were used as positive reinforcement for learning behaviour. The use of rewards was also used to build more powerful activities in the classroom.
\end{abstract}

Keywords: rewards, use of rewards, learning behaviour, self-development

\section{INTRODUCTION}

The school where the research seriously interested in playing football, and study was conducted is on the outskirts of Bangkok. The school is well-known as a generally participating in football competitions. Students who attend this football academy where students around football academy normally attend Thailand enrol in its football program. The mainstream competitions such as the majority of students in the school are Department of Physical Education Football 
Competition and PTT FA Thailand Youth Festival. So, these competitive events drive them to have a strong goal to be professional football player. Playing football becomes their first priority, and learning English is not their essential consideration and they may not consider learning the English language as an important issue for them. So, they may lack motivation for learning the English language.

In educational settings, rewarding has been known as a way to improve student performance and motivation. The use of rewards and their relation to motivation and results are focused on research. (Reed, 2001; Yukl, Latham, \& Pursell, 1976) For example, a teacher may give a student a medal for getting the highest score in an examination. In another aspect, rewards are used to promote and manage behaviour and learning. For example, a teacher may give a student a treat for entering the classroom quietly with the hope that this will increase the chance that the student will enter the room quietly next time. However, many of these rewards used in classrooms are only delivered to the students who have the highest achievement or ranking, who always win games and classroom activity competitions, and who achieve academic success in the classroom. When giving rewards focuses almost solely on these groups of students, it may adversely affect other students' learning. The other students are probably demotivated when rewards are not used in effective ways. Therefore, 'effective rewarding' is considered as an essential tool to gain motivation and a key role to drive and increase students' motivation and development in language learning and it can lead students to have positive and desirable behaviour in the English language classroom

This study has demonstrated and examined the use of reward in English language learning and as perceived by students in the classroom. Secondly, this study has discussed the use of rewards for a specific case as applied in the research group of participants.

\section{REVIEW OF RELATED LITERATURES}

2.1. Rewards, Behavior, and Motivation

Rewards are normally referred to as any contingency that may deliver a consequence such as an activity, event, or any object that may be associated with an increase in the future likelihood of a defined behavior in similar situations 
(Horner, 2009). Thorndike (1898) viewed rewards as reiterating the likelihood of reoccurrence of a behavior that has been successful; therefore rewards can also be defined as a reinforcer if its delivery increases the possibility of a behavior. According to Horner (2009), rewards are important both for enhancing appropriate behavior and preventing inappropriate behavior.

In the field of behaviourism rewarding was initially shown and developed by B.F. Skinner in the 1950s. The theory works on the premise that if reinforcement is delivered after a certain behaviour is performed, then the strength of the behaviour is increased (Cosgrove, 1982). In other words, reinforcement is any stimulus given after a behaviour that increases the chance of the behaviour recurring. For example, many teachers use the principles of operant conditioning when they give out stickers, treats, and praise. Moreover, rewards in the field of language teaching and learning were discussed in the sense of learner motivation theories.

In the field of motivation, extrinsic motivation occurs when a person completes an activity because it leads to getting an external reward. A child who is promised a trip to the movies after cleaning his room is said to be extrinsically motivated. Generally, the majority of rewards given in the classroom are extrinsic motivators, however, students will learn most when they are engaged by intrinsic motivation. The students who are intrinsically motivated show a number of behaviours that allow them to perform accordingly with their academic abilities (Spaulding, 1992). For example, students who are intrinsically motivated become involved in a task and get a feeling of enjoyment (Amabile \& Gitomer, 1984). However, researchers are concerned about the extent to which extrinsic rewards could decrease intrinsically motivated behaviour when rewards are removed.

\subsection{Reward and Self-development}

Receptivity to self-development is increased by teaching people constructive thought processes and by highlighting the value of its characteristics. One characteristic is discussed as goal orientation. This aspect affects how students perceive the goal setting of the class. Goal orientations are individual, trait-like differences that influence motivation and classroom achievement in children (Ellliot and Dweck, 1998) and adults (Schrtaw, Horn, Thorndike-Christ, 
and Bruning, 1995). The use of rewards may motivate students to achieve for an individual reason which impacts the way they engage in and respond to their learning situations. For example, students focus on being rewarded while performing important tasks until they are completed, basing one's actions on clearly defined goals, and starting and finishing tasks in a timely fashion. So, they do not give up easily to accomplish a goal, especially when the goal is important to their identity or sense of self-worth. This will lead to the internalization of the desire for positive consequences. Thus, external goals are internalized, and behavior is selfdetermined. People will be intrinsically motivated when they have a sense of selfcompetence and they believe that they control their own learning and behaviours.

\subsection{Perception of rewards}

Some researchers have found an increase in intrinsic motivation when the subjects were verbally praised subjects compared to those of a control group, (e.g. Deci, 1971) while others report no significant differences (e.g., Orlick \& Mosher, 1978). The same holds true when subjects received tangible rewards compared to the subjects in the control groups. While some results provide evidence for a decrease in intrinsic motivation following a tangible reward (e.g., Danner \& Lonkey, 1981), other researchers indicate an increase (e.g., Rosenfield, Folger, \& Adelman, 1980)

Comparisons between subjects who receive an unexpected tangible reward and subjects who receive no reward are also unclear. Some results indicate that unexpected-reward subjects show a decrease in intrinsic motivation (e.g., Orlick \& Mosher, 1978); others have found no significant differences (e.g., Greene \& Lepper, 1974). Experiments designed to investigate the effects of expected tangible rewards are also contradictory. Some studies, comparing subjects offered an expected reward to nonrewarded controls, show a negative effect of reward on intrinsic motivation (e.g., Deci, 1971; Lepper, Greene, \& Nisbett, 1973). Others, however, demonstrate that expectedreward subjects show an increase in intrinsic motivation which is in line with those of the control group (e.g., Brennan \& Glover, 1980).

Perhaps one of the most significant factors in the use of rewards is how they are perceived by teachers and students. The majority of teachers who use rewards 
believe that elementary school teachers should use rewards. Many teachers from this study explained that rewards help motivate students to exhibit good behaviour and some mentioned that rewards motivate kids to do their best work. (Hoffmann et al., 2009) Hoffmann also mentioned that teachers who used rewards for behaviour management also tended to use rewards for academic achievement, with the highest frequencies of rewards being verbal or written praise and prizes.

Mansfield (2007) shows that how pupils perceive the use of rewards and sanctions has been found to impact their sense of belonging in their school, and this in turn can affect both academic performance and social behaviour. Similarly, pupils' attachment to school is greater when teachers care, use praise and treat pupils in a way that is perceived to be fair (Hallinan 2008).

The findings derived from research studies on motivation, behaviour management and academic achievement were inconclusive. The awareness of the use of rewards should have moved away from the extrinsic motivators of rewards, and bring a new focus on a wider exploration of how learners handle their learning behaviours and development. Also, it is ironic that the studies above have rarely included the voices of students This study examined the process whereby rewards for English language learning are given in classroom settings. With a study, it explored the reward experiences of secondary school students and collected information on their pre-reward and postreward perceptions. Moreover, it examined the following issues: the various kinds of rewards that are given; the reward contingency (the basis on which rewards are given); and the reward attributions (the attributions made for receiving the rewards). Importantly, this study revealed a perspective regarding the use of rewards in the classroom by students' voice. It is important to understand the ways in which rewards were used by teachers for increasing their students' motivation to learning behaviours. Using rewards is one approach that has been used to improve self-development in the classroom, as this study indicates. 


\section{METHODS}

Given the lack of research in the area, we do not have clear expectations about the direction of the results. We would want to use a highly exploratory research approach to encourage open-endedness so that we do not predetermine the factors. This study is a largely naturalistic open-ended exploratory study. manuscript.

\section{Respondents}

The study was conducted at a public school, with a total of 29 students who were attending the 8th grade of secondary school. The participants were 16 males and 13 females. The reason why the researcher decided to conduct this study was that there was not much research conducted in higher secondary schools. The students in the study were in the class which the researcher had been teaching in order to make it practical to conduct and easily manage the research.

\section{Instruments}

The instrument employed in this study was students' reflective writing. A reflection was designed to investigate how students perceive the use of rewards for desirable behaviour and self-development. The reflection consisted of two main parts. The participants were provided with the guiding questions in each part. In the first part, questions asked participants to express their feelings and the reasons behind their stated feelings. In the second part, participants were asked to mention the rewards they were satisfied with as well as to talk about any unsatisfactory rewards. The participants were required to write the reflection for 15 minutes after finishing the class in weeks 5,9 and 12.

\section{Reward Design}

The first attempt to design a reward programme for the Fundamental English course is noted here. Tangible rewards (materials and symbolic): (1) sticker, (2) special certificate, and (3) special treat (cards edibles like chocolate and crisps, preferred activities such as listening to music, watching a movie). Intangible rewards: (1) verbal praise, (2) written comments, (3) teacher's interest, and (4) message home.

The reward programme was considered as embedded help within the two main contexts including behaviour and self-development. This would mean implementing rewards at planned situations of the course or even include rewarding situations unrelated to the plan. 


\section{Data collection procedures}

The English course lasted for 12 weeks and the course instructor and students came together at the same time and place. Each session was 50 minutes long. The classes were held bi-weekly.

In the first phase (6 weeks), they were asked to join the lessons without the rewarding programme. The content of language learning relied on the lesson plans the teacher normally used for teaching the English language. Then the participants were required to complete a reflection writing for reflecting on their learning without the use of rewards.

In the second phase, students were asked to join the class with the rewarding programme in the learning process from week 7 to week 9. Students were required to collect stickers when they accomplished the expected behaviour and selfdevelopment which were designed before starting the lessons. The students were required to write the second reflection in week 9.

The third phase was held in weeks 10 to 12 , the participants were given certificates and medals to announce their development and achievement. Finally, the participants were asked to complete the last reflection which was then used for data analysis.

\section{Data analysis}

Reflection data were analysed with the elements from thematic analysis which is the process of identifying patterns or themes within qualitative data. (Braun \& Clarke, 2006). The data was converted by indicating numbers of perceptions which were written in the reflections. The participants' written reflections were then translated by the researcher into English and thematised in order to investigate participants' perception of using rewards in the classroom.

The first step was reading, and rereading the transcripts from the writing reflections. The data were transcribed and early mentions were jotted down. Data were written as any mentions related to learning and perceiving the use of rewards in the classroom.

In the second step, the mentions were started to be thematised and coded on each segment of data that was relevant to or captured something interesting about a research question.

Thirdly, mentions were examined clearly and fitted together into a theme. At the end of this step, the mentions were organised into broader themes that seemed 
to say something specific about the research question.

Next researcher reviewed, modified and developed the preliminary themes that were identified in the third step. Did they make sense? At this point, all the data were relevant to each of them.

This is the final refinement of the themes and the aim is to identify the essence of what each theme is about. In this analysis, Table 3 contains the final mentioned themes that illustrate the relationships between students' emotion and what affected their emotion. Also, in Table 2 are the final mentioned themes that illustrate the situations of rewarding (students get rewards when they...) in the classroom.

\section{RESULTS AND DISCUSSION}

Table 1. Students' Perceptions on the Use of Rewards

\begin{tabular}{|c|c|c|c|c|c|c|}
\hline \multirow[t]{2}{*}{ Perception } & \multirow[t]{2}{*}{$\mathbf{N}$} & \multirow[t]{2}{*}{ Aspects } & \multirow[t]{2}{*}{ Sub-aspect } & \multicolumn{3}{|c|}{ Perceptions } \\
\hline & & & & Cycle 1 & Cycle 2 & $\begin{array}{c}\text { Cycle } \\
3\end{array}$ \\
\hline \multirow[t]{10}{*}{ Like } & \multirow[t]{10}{*}{29} & \multirow[t]{5}{*}{ Emotion } & Enjoyable & 29 & 59 & 71 \\
\hline & & & Excited & 7 & 12 & 14 \\
\hline & & & Relaxed & 9 & 12 & 20 \\
\hline & & & Engaged and Motivated & 0 & 21 & 43 \\
\hline & & & Not boring & 4 & 11 & 11 \\
\hline & & \multirow[t]{5}{*}{ What } & Use of reward & 3 & 63 & 78 \\
\hline & & & Games \& activities & 33 & 58 & 66 \\
\hline & & & Teaching Techniques & 2 & 12 & 17 \\
\hline & & & Teacher Personality & 4 & 13 & 15 \\
\hline & & & Learning Atmosphere & 0 & 6 & 9 \\
\hline
\end{tabular}

Dislike 0

All students $(\mathrm{N}=29)$ indicated that they were satisfied with the use of rewards in the classroom. Table 1 showed two main aspects of students' perceptions while they were studying English in the class in 3 cycles (12 weeks). All students mentioned two main aspects including emotion and what they liked when they were learning and receiving rewards. From cycle 1 to cycle 3, enjoyable emotion was mostly mentioned. Also, it was increasingly mentioned until cycle 3 of using rewards (71). Moreover, the finding showed that students got engaged and motivated, and they have positively mentioned these aspects in cycle 2 (21) and cycle 3 (43). To 
investigate what students liked in the classroom, the highest satisfaction was mentioned based on the use of reward including getting stickers, special certificates, special treats, verbal praise, and home message. In addition, games and activities were mentioned as highly satisfactory in the classroom. followed by the year (Author1 et al., 2017). Do not use footnotes. “...It's really great I could get the scores and get rewards. I really liked it. I was so excited I liked how the teacher taught because it made me relaxed. I loved when I get rewards because I felt engaged in learning. When I played games and did activities, I also felt motivated to learn..."

(Participant 2)

“...I felt enjoyable when I learned with the teacher in this semester. I loved to play games and get rewards. There were many activities. I" loved to get rewards when I played games. It was not boring. I had fun and happiness. I felt excited every time when I learn English. I was never absent for this class..."

(Participant 6)

“...I liked it because it was enjoyable and relaxed. There were a lot of new things and they made me excited and I liked getting rewards when I played games. I liked to get stickers for collecting..."

(Participant 14)
“...I liked to get rewards including stickers and candies and I liked to play games. When I collected stickers, I could exchange them for special treat cards. I felt that I wanted to keep collecting stickers..."

(Participant 19)

“...I had fun. I was relaxed and excited when I learned and did activities in the class. The atmosphere was enjoyable and exciting. I liked to get rewards, stickers, when I came to class on time. I would like the teacher to give sweets and candies. I wanted to learn English with the teacher again..."

(Participant 24)

“...wherever I was whatever I was

learning, I needed to hurry to join in the class on time because I needed to get stickers. I loved how the teacher taught, together with the techniques, and activities he used. It was so enjoyable. I liked when I got rewards and candies and I loved to played games with friends..."

(Participant 26)

It was clearly seen from the excerpts that the use of rewards can play a positive role in actual classroom practice for increasing students' positive emotions since the students mentioned the rewards used for encouraging enjoyment, excitement, and engagement when learning the language. 
Also, rewards could be a supporting factor in encouraging teaching activities and strategies in the language learning classroom as students have shown their perceptions towards getting rewards after they did language learning activities and games.

Table 2. Students' Satisfaction on Situations of rewards

\begin{tabular}{|c|c|c|c|c|}
\hline Aspects & & $\begin{array}{c}\text { Situations of rewards } \\
\text { (Students will get rewards when they...) }\end{array}$ & $\begin{array}{l}\text { Perceptions } \\
\quad(174)\end{array}$ & $\%$ \\
\hline \multirow{7}{*}{ 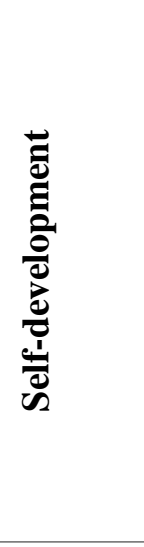 } & \multirow{13}{*}{ 窇 } & 1. Competing games (1 sticker) & 41 & 23.56 \\
\hline & & $\begin{array}{l}\text { 2. Spelling a vocabulary word and telling its } \\
\text { meaning after class (1sticker) }\end{array}$ & 29 & 16.67 \\
\hline & & $\begin{array}{l}\text { 3. Collecting stickers to get a special treats } \\
\text { cards relying on developmental rates ( } 20 \\
\text { stickers) }\end{array}$ & 22 & 12.64 \\
\hline & & 4. Putting effort to learn (1 sticker) & 17 & 9.77 \\
\hline & & 5. Completing tasks in the class (5 stickers) & 16 & 9.20 \\
\hline & & $\begin{array}{l}\text { 11. Having a better developmental rate to get } \\
\text { praise from parents }\end{array}$ & 5 & 2.87 \\
\hline & & $\begin{array}{l}\text { 12. Completing the learning programme to } \\
\text { receive a certificate and medal }\end{array}$ & 2 & 1.15 \\
\hline \multirow{7}{*}{ 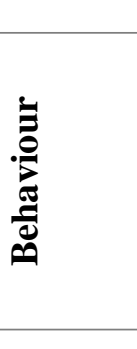 } & & Total & 132 & 75.86 \\
\hline & & 6. Being on time (1 sticker) & 18 & 10.34 \\
\hline & & 7. Participating in class activities (1) & 9 & 5.17 \\
\hline & & 8. Answering questions (1 sticker) & 10 & 5.75 \\
\hline & & $\begin{array}{l}\text { 9. Bringing learning stuff into the class } \\
\text { (1 sticker) }\end{array}$ & 4 & 2.30 \\
\hline & & 10. Being helpful to a teacher (1 sticker) & 1 & 0.57 \\
\hline & & Total & 42 & 24.14 \\
\hline
\end{tabular}

Table 2 identified the specific situations of rewards valued as satisfaction by students. It showed frequency counts for perceptions divided into two aspects: self-development and behaviour. The top three perceptions in self-development aspects related to competing games (23.56), spelling a vocabulary word and telling its meaning after class (16.67), and collecting stickers to get special treats cards relying on developmental rates (12.64). The rewards that were of the least importance seemed to be having a better developmental rate to get praise from parents (2.87) and completing the learning programme to receive certificate and medal (1.15). The next two highest-rated mentions were of behaviour aspect: be on time (10.34) and answer questions (5.75). 
The least rating perceptions were related to bringing learning stuff (2.30) and being helpful for a teacher (0.57).

“...I liked rewards like stickers and candies because I got them from playing games, answering questions, and being on time ..."

(Participant 4)

“...I did not feel sleepy and I felt enjoyable when I got rewards after I competed in games in the class..."

(Participant 13)

“...I loved when I played games and got stickers. I liked to do many activities and spelling vocabulary to get stickers. It made me happy and enjoyable. I felt motivated..."

(Participant 23)

“...certificates and medals reflected what I have done for this class. I was proud of myself to get them. It encouraged me to learn English language..."

(Participant 23)
Interestingly, rewards played a significant role in the games used in the language learning classroom. To be motivated, the students needed to enjoy learning the L2. Games had the most influence on this. The language learning class was interesting and Rewards could make games and activities challenging, yet enjoyable, for the students. To compete in games, it was also significant that student could set personal goals of how to succeed in the games and activities in the classroom and make the achievement. The result showed that linking rewards to achievement of challenging standards (or mastery) may also be an effective way to increase people's motivation (Pierce et al., 2003).

Table 3. Students' lower-ranked satisfaction on the preference of rewards

\begin{tabular}{|c|c|c|c|}
\hline Aspects & Preference of rewards & $\begin{array}{l}\text { Perceptions } \\
\quad(43 / 58)\end{array}$ & $\%$ \\
\hline \multirow{6}{*}{ 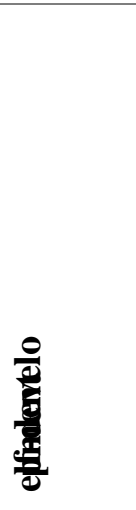 } & 1. Competing in games & 0 & 0.00 \\
\hline & $\begin{array}{l}\text { 2. Spelling a vocabulary word and telling its meaning after } \\
\text { class }\end{array}$ & 26 & 60.47 \\
\hline & $\begin{array}{l}\text { 3. Collecting stickers to get special treats cards relying on } \\
\text { developmental rates }\end{array}$ & 1 & 2.33 \\
\hline & & & 0.00 \\
\hline & & & 6.98 \\
\hline & 4. Putting effort to learn & 0 & 2.33 \\
\hline \multirow[b]{2}{*}{$\infty$} & 5. Completing tasks in the class & 3 & \\
\hline & $\begin{array}{l}\text { 6. Having a better developmental rate to get praise from } \\
\text { nnmantc }\end{array}$ & 1 & 0.00 \\
\hline
\end{tabular}




\begin{tabular}{|c|c|c|c|}
\hline & Total & 31 & 72.09 \\
\hline \multirow{5}{*}{ 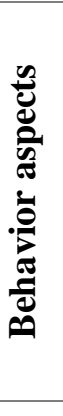 } & 8. Being on time & 1 & 2.33 \\
\hline & 9. Participating in class activities & 0 & 0.00 \\
\hline & 10. Answering questions & 7 & 16.28 \\
\hline & & 4 & 9.30 \\
\hline & 11. Bringing learning stuff into the class & 1 & 2.33 \\
\hline & 11 Dnins holnfirl ton tamahnn & 13 & 30.23 \\
\hline
\end{tabular}

In contrast, students' lower-ranked satisfaction on the preference of rewards was related to spelling vocabulary word for 26 from 58 mentions (60.47). The findings also showed that answering questions was unsatisfactory for receiving rewards in the class in terms of behaviour aspect (16.28).

The researcher had hoped to shed some light on ways to increase students' selfdevelopment and learning behaviour by giving rewards to students who could achieve the spelling of vocabulary terms and answering questions. The results, however, indicated making mistakes among peers and the teacher was considered unsatisfactory as a rewarding aspect for students. The factors were relevant to examples of Covington's (2001) prosocial goals: fear of looking bad to the instructor, competing with other students for doing well, and fear of looking bad to other students.

This study showed the perceptions regarding the use of rewards in the classroom by investigating how students perceived the use of rewards. The insight in this study may provide a better understanding of how, whether, and under what situations/circumstances rewards can play a positive role in actual classroom practice. One effective way of getting a complete picture of how they perceive the use of rewards in the classroom was obtained by including reflective journal writing. Also, this study employed 29 students in the same classroom who have different learning traits and social backgrounds.

All of the participants in this study reported receiving rewards in their classroom. All students $(\mathrm{N}=29)$ perceived that they were satisfied with the use of rewards in the classroom. They mostly felt that they enjoyed learning in the classroom. This finding directly supports those who advocate using rewards in the classroom. Students who are intrinsically motivated become involved in the task and get a feeling of enjoyment (Amabile and Gitomer, 1984). 
Okan (2003) also draws attention to these effects, particularly to the expectation in the learners that the process of learning should always be colourful and fun, and that they can acquire information without work and serious study. Regarding the use of tangible rewards including getting stickers, special certificates, and special treat cards, the use of rewards in activities and games was ranked highly in their satisfaction ranking in the classroom. Halverson, and Gee (2004) argue for a particular view of games and of learning as activities that are most powerful when they are personally meaningful, experiential, social, and epistemological.

Students also perceived the use of rewards as they got engaged and motivated since they have significantly mentioned these aspects in cycle 2 since the use of rewards, games and activities are the most engaging and motivating factors. There was a significant association between the use of rewards and games and activities, which suggests that rewards are used as a motivational factor supporting games and activities used in the classroom. Cameron et al. (2005) believed that intrinsic and external sources of motivation contribute to motivation for an activity. "Giving rewards for successful achievement on an activity leads individuals to perform high task interest and to be motivated to perform the activity and other similar tasks in the future" (Cameron et al., 2005, p.654).

In order to highlight key aspects of the behaviour theme, it is obviously seen that students reflected the highest scoring on being on time and answering questions. This showed that the use of rewards worked as reinforcement. This is related to the premise that if reinforcement is delivered after a certain behaviour is performed, then the strength of the behaviour is increased (Cosgrove, 1982). Also, Zlomke and Zlomke (2003) found that negative behaviours were reduced when students earned points for displaying positive behaviour and then exchanged these points for a reward.

Another finding that provides important implications was that rewards should be used carefully; they can play a role in students' self-development. While it is unclear from the ongoing debates that rewards are used for self-development, there are some guidelines from this study and previous relevant research studies. In this study, rewards play a role to motivate students to achieve for the individual reason which impacts the way they engage in and respond to their learning situations. The participants reflected on themselves as they perceived that they did not feel sleepy or bored in the class. Moreover, they 
mentioned the aspects of emotion which indicated that the more they enrolled in the class rewards given, the more they felt enjoyed and engaged in the learning in the classroom. The previous ideas indicated that rewards were used as environmental and emotional support which can empower selfdevelopment, especially for individuals who respond positively to such an environment. Rewards may motivate students to achieve their learning goals for the individual reason which impacts the way they engage in and respond to their learning situations. Another guideline from previous research studies was goal orientations. Another study by SelfBrown and Mathews (2003) indicated that in a classroom with supportive factors of performance goals and efforts, students had higher rates of task motivation and learning goals. Thus, external goals from the reward given are internalized. People will be intrinsically motivated when they have a sense of self-competence and they believe that they control their own learning and behaviours. Another goal orientation, performance orientation, was found as the orientation where a student sought to show greater competence in social comparison which was related to more positive outcomes in terms of task value and self-efficacy (Wolters et al., 1996).
Concerning the students' perceptions included in this study, an interesting finding emerged that positive consequences were derived from the use of rewards in the classroom. All students were satisfied with the use of rewards by positively mentioning enjoyment, excitement, engagement and higher motivation in learning the English language. So, what influenced those emotions emerged as the use of tangible rewards including stickers, special certificates, special treats, and intangible rewards including verbal praise, and home message. The activities and games integrated with the use of rewards were also highly considered as enhancing students' satisfaction in learning. In terms of learning behaviours, this study showed that the use of rewards worked as reinforcement which seemed to increase their learning behaviours such as being on time and answering questions in the classroom. Yet it was not surely revealed that learning behaviour would be still maintained when rewards were removed. To pay attention to selfdevelopment, external rewards played a role to support the learning environment and emotions. For this reason, the use of rewards could empower self-development by motivating students to achieve their learning goals. 


\section{CONCLUSIONS}

This study can highlight that the use of rewards was perceived as a tool for enhancing motivation, learning behaviours, and self-development. The present findings suggest that the use of rewards enhances students' engagement in learning. So many students lack motivation in learning the language. The use of rewards can also play a role in the classroom as a positive reinforcement to increase the learning desire behaviour. So, the use of rewards should be thoughtfully designed to suit students' learning goals and behaviour. Measuring the success of rewarding desired behaviors is complex depending on a number of variables such as the size of the reward, schedule of reward, contingencies in the environment, and other factors such as gender and environmental factors. In addition, rewards are used to build more powerful activities and games in the classroom. Thus, the rewards used would build an environment of learning and positive emotion since emotional states or moods influence behaviors, learning, perceptions, memory, and judgment (Dörnyei, Z., 2009). Another possibility regarding rewards is that it can enhance self-development if teachers use rewards as external goals. The use of rewards need not be limited to high academic achievement students, but also with students who perceive their own development which means that teachers should not use rewards only for the winner of the class. The main hypothesis has been that one way to achieve this goal is to use positive reinforcement and conditioning in the form of relevant, immediate incentives that will lead students to cultivate an interest in the subject matter. Students will be intrinsically motivated when they have a sense of self-competence and they believe that they control their own learning and behavioural goals.

Rewards can have a negative impact on learning when they are offered to people for engaging in a task without consideration of any system. In a classroom, this might occur if a teacher promised students tangible rewards simply for doing an activity. For example, a teacher who promises stickers or other awards to students who put effort into learning language may undermine intrinsic motivation. In such a case, one could expect rewarded individuals to enjoy the task as much as those who are not offered an incentive. But they may spend less time on the activity in a study period when the reward is no longer forthcoming. According to the results of this study, learning behaviour and self-development would not be seen in the class if the teacher used the 
same rewards but made them contingent on

successful completion of the various

learning situations.

\section{REFERENCES}

Adlina A., Samada A, \& Etemadzadehb Hamid R. F. (2012). Motivation and Language Proficiency: Instrumental and Integrative Aspects. Elsevier Ltd, 66, 432 - 440.

Arkoosh, M., Weber, K., \& McLaughlin T.F. (2009). The Effects of Motivational/Reward System and a Spelling Racetrack on Spelling Performance in General Education: A Case Report. The Open Education Journal: Department of Special Education, Gonzaga University, 2, 17-20.

Cameron, J., \& David Pierce, W. (1994). Reinforcement, Reward, and Intrinsic Motivation: A Meta-Analysis. Review of Educational Research, 64, 363-423.

Cameron, J., David Pierce, W., Katherine, M. B., \& Gear, A. (2005). Achievement-Based Rewards and Intrinsic Motivation: A Test of Cognitive Mediators. Journal of Educational Psychology. University of Alberta, 97, 641-655.

Ching, Gregory S. (2012). Looking into the issues of rewards and punishment in students International Journal of Research Studies in Psychology. Lunghwa University of Science and Technology, Taiwan, 1, 29-38.

Daniel O' leary K., \& RONAL D. (1971). Token Reinforcement Programs in the Classroom. Psychological Bulletin, 75, 379-398.

David H., Nicholas B., Mathew C. N., \& Sarah W. S. (2016). Using Variable Interval Reinforcement Schedules to Support Students in the Classroom: An Introduction With Illustrative Examples. Journal of Education Research and Practice, 26, 90-96.

Dörnyei, Z. (2000). Motivation and motivation theories. In M. Byram (Ed.), 425-435.

Dörnyei, Z. (2009). Motivation and the vision of knowing a second language. In B. Beaven (Ed.), IATEFL 2008: Exeter conference selections, 16-22.

Drexler J. (2010). Teachers' Attitudes about Reward Systems in the Classroom. Education and Human Development, The College at Brockport.

Kristin, F. H., Jessica. H., Ashley S. P., \& John L. N. (2009). Elementary teachers' use and perception of rewards in the classroom. Teaching and Teacher Education, 25, 843849.

Lucy M., \& Richard M. (2014). Shaping Student Behaviors Through Reward Systems: 
Lessons From Beaver Trapping?. Journal of Higher Education Theory and Practice, 14, 89-102.

Manuel L., \& Lames W. S. (1999). Empower Self-development and Continuous Learning. Human Resource Management, 38, 3-15.

Moira M., \& Bird D. (2017). Doing Thematic Analysis: A Practical, Step-by- Step Guide for Learning and Teaching Scholar. Dundalk Institute of Technology, 8, 1-12.

Pae, T. (2008). Second Language Orientation and Self-Determination Theory: A Structural Analysis of the Factors Affecting Second Language Achievement. Journal of Language and Social Psychology, 27, 5-27.

Payne, R. (2015). Using rewards and sanctions in the classroom: pupils' perceptions of their own responses to current behaviour management strategies. Routledge Taylor and Francis Group, 67, 483-504.

Rachel E. C. (1987). Rewards and Punishment in Schools: A study of their Effectiveness as Perceived by Secondary School Pupils and Their Teachers. School of Psychology International, 8, 85-94.

$\mathrm{Wu}, \mathrm{X}$. (2003). Intrinsic motivation and young language learners: the impact of the classroom environment. System, 31, $501-517$. 